\title{
Modeling the Volatility of the Dow Jones Islamic Market World Index Using a Fractionally Integrated Time Varying GARCH (FITVGARCH) Model
}

\author{
Adnen Ben Nasr * Ahdi Noomen Ajmi ${ }^{\dagger} \quad$ Rangan Gupta ${ }^{\ddagger}$
}

\begin{abstract}
Appropriate modeling of the process of volatility has implications for portfolio selection, the pricing of derivative securities and risk management. Further, a large body of research has suggested that both long memory and structural changes simultaneously characterize the structure of financial returns volatility. Given this, in this paper, we aim to model conditional volatility of the returns of the Dow Jones Islamic Market World Index (DJIM), interest on which has come to the fore following the need for renovation of the conventional financial system, in the wake of the recent global financial crisis. To model the conditional volatility of the DJIM returns, accounting for both long memory and structural changes, we allow the parameters in the conditional variance equation of the Fractionally Integrated Generalized
\end{abstract}

${ }^{*}$ Laboratoire BESTMOD, ISG de Tunis, Université de Tunis, Tunisia, email:adnen.bennasr@isg.rnu.tn

${ }^{\dagger}$ College of Science and Humanities in Slayel, Salman bin Abdulaziz University, Kingdom of Saudi Arabia, email: ajmi.ahdi.noomen@gmail.com

${ }^{\ddagger}$ Corresponding author: Department of Economics, University of Pretoria, Pretoria 0002, South Africa, email: Rangan.Gupta@up.ac.za 
Autoregressive Conditional Heteroskedasticity (FIGARCH) model to be time dependent, such that the parameters evolve smoothly over time based on a logistic smooth transition function, yielding a Fractionally Integrated Time Varying Generalized Autoregressive Conditional Heteroskedasticity (FITVGARCH) model. Our results show that, in terms of model diagnostics and information criteria, the FITVGARCH model performs better than the FIGARCH model in explaining conditional volatility of the DJIM returns, thus, highlighting the need to model simultaneously long-memory and structural changes in the volatility process of asset returns.

Keywords : Volatility modeling; Long memory; Structural changes; Model specification 


\section{Introduction}

The recent global financial crisis has exerted enormous negative impacts on conventional financial institutions and markets. Hence, a need has been felt for a renovation of the conventional financial systems through creating viable alternatives that allow opportunities to reduce investment risks, increase returns, enhance financial stability, and reassure investors and financial markets. Given this, following the crisis, one has observed a steady increase in renewed interest in Islamic finance, ${ }^{1}$ based on Sharia rules, as a viable financial system that can be used as an opportunity to diversify away the systematic risk in conventional portfolios. In essence, it is believed that Islamic finance may offer products and instruments that are driven by greater social responsibility, ethical and moral values, and sustainable finance, and hence, can possibly endure financial crises better than the conventional system.

Against this backdrop, in this paper, we aim to model conditional volatility of the returns of the Dow Jones Islamic Market World Index (DJIM), accounting for both long memory and structural changes in the volatility process. The choice of the DJIM is justified by the fact that it is the most widely used, most comprehensive representative, and has the most adequate time series for the Islamic stock market (Hammoudeh et al., 2013). Note that, appropriate modeling of volatility is of importance due to several reasons: (i) When volatility is interpreted as uncertainty, it becomes a key input to many investment decisions and portfolio creations. Given that, investors and portfolio managers have certain bearable levels of risk, proper modeling (and forecasting) of the volatility of asset prices over the investment holding

\footnotetext{
${ }^{1}$ Assets in the Islamic industry have grown $500 \%$ in the last five years and reached 1.6 trillion U.S. dollars in 2013 (Hammoudeh et al., 2013).
} 
period is of paramount importance in assessing investment risk; (ii) Volatility is the most important variable in the pricing of derivative securities. To price an option, one needs to know the volatility of the underlying asset from now until the option expires; (iii) Financial risk management has taken a dominant role since the first Basle Accord was established in 1996, making proper modeling (and forecasting) of volatility a compulsory risk-management exercise for financial institutions around the world. Finally, financial market volatility, as witnessed during the recent "Great Recession" for the returns on DJIM (see Figure 1), can have a wide repercussion on the economy as a whole, via its effect on public confidence. Hence, market estimates of volatility can serve as a measure for the vulnerability of financial markets and the economy, and help policy makers to design appropriate policies. Evidently, appropriate modeling of the process of volatility has implications for portfolio selection, the pricing of derivative securities and risk management. A large body of research suggests that there is significant evidence of long memory in the conditional volatility of various financial and economic time series (Ding et al., 1993; Baillie et al., 1996; Andersen and Bollerslev, 1997; Bollerslev and Mikkelsen, 1996; Lobato and Savin, 1998; Davidson, 2004). Another related discussion on financial time series suggests that there is strong evidence for the occurrence of structural changes in the volatility process(Bos et al., 1999; Andreou and Ghysels, 2002; Rapach and Strauss, 2008; Rapach et al., 2008). ${ }^{2}$ In light of these two features (long memory and structural

\footnotetext{
${ }^{2}$ A related line of research on long memory and structural changes in the volatility discusses the connection between these phenomena. In fact, the volatility persistence may be due to structural breaks in the volatility process, as first suggested by Diebold (1986) and Lamoureux and Lastrapes (1990). This literature concludes that it is very difficult to distinguish between true and spurious long memory processes. However, recent contributions to this literature have attempted to discriminate between long memory and structural
} 
breaks), a body of research has suggested that both long memory and structural changes simultaneously characterize the structure of financial returns volatility (Lobato and Savin, 1998; Beine and Laurent, 2000; Morana and Beltratti, 2004; Martens et al., 2004; Baillie and Morana, 2007).

Motivated from the line of research that suggests the co-existence of both long memory and structural change in the volatility process of financial markets data, following Ben Nasr et al., (2010), we estimate a model for the DJIM returns that allows the volatility of the returns to have such behaviors. The idea is to allow the parameters in the conditional variance equation of the Fractionally Integrated Generalized Autoregressive Conditional Heteroskedasticity (FIGARCH) model to be time dependent. More precisely, the change of the parameters is assumed to evolve smoothly over time using a logistic smooth transition function, to yield us a Fractionally Integrated Time Varying Generalized Autoregressive Conditional Heteroskedasticity (FITVGARCH) model. Our results show that, in terms of model diagnostics and information criteria, the FITVGARCH model performs better than the FIGARCH model in explaining conditional volatility of the DJIM returns. To the best of our knowledge, this is the first attempt in modeling the volatility process for the DJIM returns. The rest of the paper is organized as follows: Section 2 discusses the basics of the FITVGARCH model, while Section 3 presents the data and the empirical results. Finally, Section 4 concludes. changes in the volatility process (Stărică and Granger, 2005; Mikosch and Stărică, 2005; Perron and Qu, 2007; 2008). 


\section{The Fractionally Integrated Time Varying GARCH (FITVGARCH) Model}

\subsection{The econometric framework}

The Fractionally Integrated Time Varying GARCH (FITVGARCH) model was introduced by Ben Nasr et al. (2010) as an extension of the FIGARCH model of Baillie et al. (1996) by allowing the conditional variance parameters to change over time. In fact, this new long memory model is capable of detecting instability in the volatility structure, which makes it an interesting tool for modeling financial market time series, exhibiting jointly long memory and structural change in their dynamic properties over time.

The $\operatorname{FiTVGARCH}(p, d, q)$ model is given by:

$$
\begin{aligned}
y_{t} & =\varepsilon_{t} \\
\varepsilon_{t} & =\eta_{t} h_{t}^{1 / 2}, \quad \eta_{t} \sim N(0,1) \\
{\left[1-\phi_{t}(L)\right](1-L)^{d} \varepsilon_{t}^{2} } & =\omega_{t}+\left[1-\beta_{t}(L)\right] v_{t}
\end{aligned}
$$

where $y_{t}$ is the time series, $h_{t}$ is the conditional variance, $v_{t}=\varepsilon_{t}^{2}-h_{t}$, $\omega_{t}=\omega_{1}+\omega_{2} F\left(t^{*} ; \gamma, c\right), \phi_{t}(L)=\phi_{1}(L)+\phi_{2}(L) F\left(t^{*} ; \gamma, c\right) ; \phi_{1}(L)=\phi_{1,1} L+$ $\ldots+\phi_{1, q} L^{q}, \phi_{2}(L)=\phi_{2,1} L+\ldots+\phi_{2, q} L^{q}, \beta_{t}(L)=\beta_{1}(L)+\beta_{2}(L) F\left(t^{*} ; \gamma, c\right)$; $\beta_{1}(L)=\beta_{1,1} L+\ldots+\beta_{1, p} L^{p}, \beta_{2}(L)=\beta_{2,1} L+\ldots+\beta_{2, p} L^{p}, F\left(t^{*} ; \gamma, c\right)$ is a logistic smooth transition function defined as

$$
\begin{gathered}
F\left(t^{*} ; \gamma, c\right)=\left(1+\exp \left\{-\gamma \prod_{k=1}^{K}\left(t^{*}-c_{k}\right)\right\}\right)^{-1}, \\
\gamma>0, \quad c_{1} \leq c_{2} \leq \ldots \leq c_{K} .
\end{gathered}
$$

where the transition variable is the standardized time variable $t^{*}=t / T$ and $T$ is the sample size. The transition function $F\left(t^{*} ; \gamma, c\right)$ is a continuous 
function bounded between 0 and 1 . The parameter $\gamma$ corresponds to the speed of transition between the two regimes, while the parameter $c_{k}$, known as the threshold parameter, indicates when, in the range of $t$, the transition takes place.

The roots of the polynomials $\left[1-\phi_{t}(L)\right]$ and $\left[1-\beta_{t}(L)\right]$ are outside the unit circle for all $t$. This implies that $\left[1-\phi_{t}(1)\right]>0$ and $\left[1-\beta_{t}(1)\right]>0$. With $K=1$, the parameters of the FIGARCH model change smoothly over time from $\left(\omega_{1}, \phi_{1, i}, \beta_{1, j}\right)$ to $\left(\omega_{1}+\omega_{2}, \phi_{1, i}+\phi_{2, i}, \beta_{1, j}+\beta_{2, j}\right), i=1, \ldots, q, j=1, \ldots, p$. The transition between regimes happens instantaneously when $t^{*}=c_{1}$ and $\gamma$ is large. When $\gamma \rightarrow 0$, the $\operatorname{FITVGARCH}(p, d, q)$ model in (3) nests the FIGARCH $(p, d, q)$ model of Baillie et al. (1996) since the logistic transition function becomes constant and equal to $1 / 2$. Now, we will see how to test whether the $\operatorname{FITVGARCH}(p, d, q)$ specification could be suitable for the data.

\subsection{Testing parameter constancy}

The null hypothesis of parameters constancy can be expressed as equality of the FIGARCH parameters in the two regimes. As in Lin and Teräsvirta (1994), Eitrheim and Teräsvirta (1996), the alternative hypothesis is that the parameters may change smoothly over time. Thus, the null hypothesis can be stated as $H_{0}: \gamma=0$ against alternative hypothesis $H_{1}: \gamma>0$. Testing for parameter constancy is complicated because of the existence of unidentified nuisance parameters under the null hypothesis $H_{0}$. More explicitly, when $\gamma=0, F\left(t^{*} ; \gamma, c\right)=1 / 2$. This makes the parameters $\gamma$ and $c$ not identified when the null hypothesis is valid. The identification problem is circumvented, following Luukkonen et al. (1988), using a Taylor expansion for the transition function about $\gamma=0$. In practice, the LM test of parameter constancy may be carried out using the following steps: 
1- Estimate the parameters of the conditional variance under the null hypothesis and compute $\hat{u}_{t}=\left(\frac{\hat{\epsilon}_{t}^{2}}{\hat{h}_{t}^{0}}-1\right), t=1, \ldots, T$, and the sum of squares $S S R_{0}=\sum_{t=1}^{T} \hat{u}_{t}^{2}$.

2- Regress $\hat{u}_{t}$ on $\hat{z}_{1, t}$ and $\hat{z}_{2, t}, t=1, \ldots, T$ and compute the sum of squared residuals $S S R_{1}{ }^{3}$.

3- Compute the $L M$ test statistic as

$$
L M_{K}=T \frac{S S R_{0}-S S R_{1}}{S S R_{0}}
$$

Under the null hypothesis, the statistic $L M_{K}$ of parameter constancy test is $\chi^{2}$ distribution with $K(p+q+1)$ degrees of freedom. If the null hypothesis of parameter constancy against smoothly changing parameters is rejected, one can conclude that the structure of the conditional variance of the process is changing over time.

\subsection{Estimation}

When the null hypothesis of parameter constancy is rejected, we can estimate the FITVGARCH model using the Quasi Maximum Likelihood (QML) estimation procedure which was adapted by Baillie et al.(1996) to estimate the FIGARCH model. The QML estimates obtained with the assumption that the innovations are normally distributed behave relatively well. Consequently, the estimates for the parameters may be obtained by maximizing the following Gaussian log-likelihood function

\footnotetext{
${ }^{3} \hat{z}_{1, t}$ and $\hat{z}_{2, t}$ are the partial derivatives of the conditional variance $h_{t}$ with respect to $\theta_{1}$ and $\theta_{2}$, respectively, where $\theta=\left(\theta_{1}^{\prime}, \theta_{2}^{\prime}\right)^{\prime}$ is the vector of parameters in the conditional variance equation obtained by replacing the logistic transition function by its Taylor expansion around $\gamma=0$ and such that $\theta_{2}=0$ under $H_{0}$. For more details, see Ben Nasr et al. (2010), pp408-410.
} 


$$
l(\theta)=-\frac{T}{2} \log 2 \pi-\frac{1}{2} \sum_{t=1}^{T}\left[\log \left(h_{t}\right)+\frac{\varepsilon_{t}^{2}}{h_{t}}\right]
$$

where $\theta=\left(\omega_{1}, \phi_{1}^{\prime}, \beta_{1}^{\prime}, \omega_{2}, \phi_{2}^{\prime}, \beta_{2}^{\prime}, c, \gamma, d\right)^{\prime}$ is the parameter vector of the FITVGARCH model.

\subsection{Misspecification tests}

At the evaluation stage, the estimated FITVGARCH model is subjected to misspecification tests. In this section we focus on testing serial dependence in the squared standardized errors. We use the test proposed by Lundbergh and Teräsvirta (2002) as a parametric LM type tests of no ARCH in standardized errors. This test was adapted to FITVGARCH model in Ben Nasr et al. (2010) by assuming that the misspecification structure in this model has the additive form

$$
\begin{aligned}
h_{t}= & \omega_{1}+\left[1-\beta_{1}(L)-\left(1-\phi_{1}(L)\right)(1-L)^{d}\right] \varepsilon_{t}^{2}+\beta_{1}(L) h_{t} \\
& +\left(\omega_{2}+\left[\phi_{2}(L)(1-L)^{d}-\beta_{2}(L)\right] \varepsilon_{t}^{2}+\beta_{2}(L) h_{t}\right) F\left(t^{*} ; \gamma, c\right) \\
& +\pi^{\prime} \nu_{t}
\end{aligned}
$$

where $\nu_{t}=\left(\eta_{t-1}^{2}, \ldots, \eta_{t-r}^{2}\right)^{\prime}$ and $\pi=\left(\pi_{1}, \ldots, \pi_{r}\right)^{\prime}$. The null hypothesis of no serial dependence in $\eta_{t}^{2}$ up to the $r$-th order is defined as $H_{0}: \pi_{1}=\pi_{2}=$ $\ldots=\pi_{r}=0$. In practice, the $L M$ test for $r$ th-order serial dependence in the squared standardized errors can be performed in three stages as follows:

1- Estimate the parameters of the FITVGARCH model under the null hypothesis and compute $\hat{u}_{t}=\left(\frac{\hat{\varepsilon}_{t}^{2}}{\hat{h}_{t}^{0}}-1\right), t=1, \ldots, T$, and the sum of squares $S S R_{0}=\sum_{t=1}^{T} \hat{u}_{t}^{2}$. 
2- Regress $\hat{u}_{t}$ on $\hat{z}_{1, t}$ and $\hat{z}_{2, t}, t=1, \ldots, T$ and compute the sum of squared residuals $S S R_{1}^{4}$.

3- Compute the $L M$ test statistic as

$$
L M=T \frac{S S R_{0}-S S R_{1}}{S S R_{0}}
$$

which under the null hypothesis is approximately $\chi^{2}$ distributed with $r$ degrees of freedom.

\section{Empirical results}

\subsection{Data}

In this subsection, the FITVGARCH model is estimated for the Global Dow Jones Islamic Market World Index (DJIM). The data spans the period of January 1, 1996 to July 22, 2013, implying a total of 4,579 daily observations. Note that, the start and end date for the index is governed purely by data availability at the time of writing this paper. The time series for the index is sourced from Bloomberg. The DJIM index measures the global universe of investable equities that have been screened for Sharia compliance. The companies in this index pass the industry and financial ratio screens. The regional allocation for DJIM is classified as follows: $60.14 \%$ for the United States; $24.33 \%$ for Europe and South Africa; and $15.53 \%$ for Asia (Hammoudeh et al., 2013). In order to get a preliminary idea about the data set, we present, in Figure 1, the daily index in levels and returns, as well as,

\footnotetext{
${ }^{4} \hat{z}_{1, t}$ and $\hat{z}_{2, t}$ are the partial derivatives of the conditional variance $h_{t}$ in (6) with respect to $\theta$ and $\pi$, respectively, where $\theta=\left(\omega_{1}, \phi_{1}^{\prime}, \beta_{1}^{\prime}, \omega_{2}, \phi_{2}^{\prime}, \beta_{2}^{\prime}, c, \gamma, d\right)^{\prime}$ and $\pi=\left(\pi_{1}, \ldots, \pi_{r}\right)^{\prime}$.
} 
DJIM index

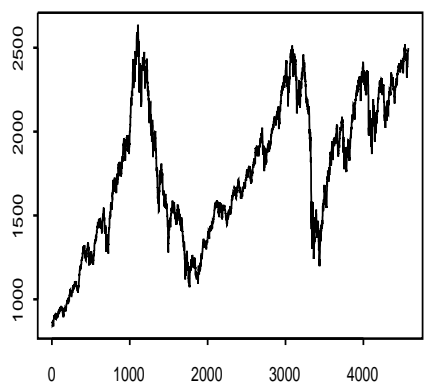

ACF-Daily returns

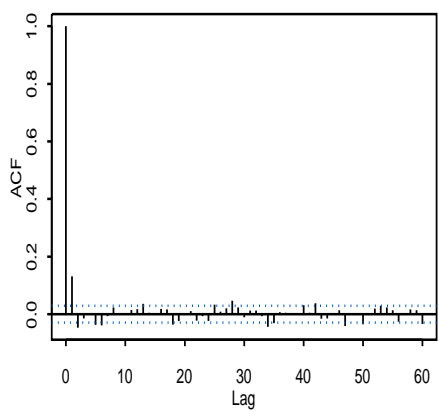

DJIM returns

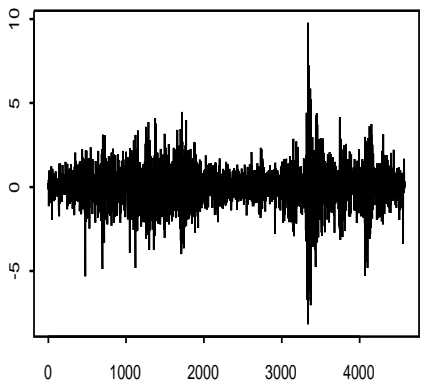

ACF-Squared daily returns

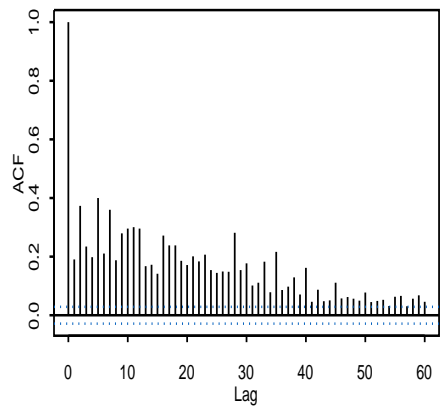

Figure 1: Graphical presentation of DJIM index, returns and autocorrelation.

the autocorrelation functions for daily returns and for daily squared returns. Note that daily returns are obtained by taking 100 times the first difference of the natural $\log$ of the index. The plot in the upper panel shows that daily returns are, in general, highly volatile, with it being highest during the month of October in 2008.

Examination of the sample autocorrelation functions for daily returns and for daily squared returns, illustrated in the lower panel of Figure 1, indicates that daily returns seem to be slightly autocorrelated, especially with positive autocorrelation at lag 1 and with weak negative autocorrelation at lag 2 . 
Table 1: LM-type tests for parameter constancy of FIGARCH model against FI-TVGARCH model

\begin{tabular}{lll}
\hline$L M_{k}$ & LM statistic & $p$-value \\
\hline$L M_{1}$ & 5.800 & 0.1217 \\
$L M_{2}$ & 15.8328 & 0.0147 \\
$L M_{3}$ & 17.1142 & 0.0469 \\
\hline
\end{tabular}

Note: The table contains LM statistics and $p$ values of parameter constancy test where $L M_{K}$, $K=1,2$ and 3 , denotes the LM-type test for parameter constancy based on the $K$ th-order logistic smooth transition regression.

However, the autocorrelations of the squared returns show strong temporal dependence and exhibit a hyperbolic rate of decay. These features may suggest that long-range dependence of squared returns could be modeled by a fractionally integrated process. Thus, we propose to use the Autoregressive Moving Average (ARMA) and the FITVGARCH to model the mean and the volatility processes respectively. The FITVGARCH model is able to capture both long memory and structural change in the volatility process. To identify the ARMA structure, we use the Bayesian Information Criterion (BIC). After fitting various $A R M A(p, q)$ models to the mean returns, the lowest BIC value is obtained for $p=2$ and $q=0$.

\subsection{Testing for parameter constancy}

We begin the modelling procedure by testing parameter constancy in the standard FIGARCH$(1, d, 1)$ model, applied to the residuals from the $\operatorname{AR}(2)$ model, against smoothly changing parameters (FITVGARCH $(1, d, 1)$ model).

The results are given in Table 1 . The null hypothesis of parameters con- 
stancy is rejected at $5 \%$ level for $K=2,3$. We conclude that there is evidence of change over time in the FIGARCH parameters and thus the FITVGARCH model may be a correct model to use for the data.

\subsection{Estimation results}

Table 2: Summary of estimated models for DJIM daily index returns

\begin{tabular}{|c|c|c|c|c|}
\hline Parameters & \multicolumn{4}{|c|}{$\operatorname{AR}(2)$} \\
\hline$\alpha_{0}$ & \multicolumn{2}{|l|}{0.0215} & \multicolumn{2}{|l|}{$(0.0156)$} \\
\hline$\alpha_{1}$ & \multicolumn{2}{|l|}{0.1399} & \multicolumn{2}{|l|}{$(0.0148)$} \\
\hline \multirow[t]{2}{*}{$\alpha_{2}$} & \multicolumn{2}{|l|}{-0.0652} & \multicolumn{2}{|l|}{$(0.0148)$} \\
\hline & \multicolumn{2}{|c|}{$\operatorname{FITVGARCH}(1, d, 1)$} & \multicolumn{2}{|c|}{$\operatorname{FIGARCH}(1, d, 1)$} \\
\hline$\hat{d}$ & 0.474 & $(0.050)$ & 0.489 & $(0.043)$ \\
\hline$\hat{c}$ & 0.732 & $(0.029)$ & - & - \\
\hline$\hat{\gamma}$ & 96.907 & $(302.313)$ & - & - \\
\hline$\hat{\omega}_{1}$ & 0.028 & $(0.005)$ & 0.030 & $(0.004)$ \\
\hline$\hat{\phi}_{1,1}$ & 0.092 & $(0.031)$ & 0.027 & $(0.025)$ \\
\hline$\hat{\beta}_{1,1}$ & 0.530 & $(0.056)$ & 0.503 & $(0.050)$ \\
\hline$\hat{\omega}_{2}$ & 0.004 & $(0.015)$ & - & - \\
\hline$\hat{\phi}_{2,1}$ & -0.249 & $(0.077)$ & - & - \\
\hline$\hat{\beta}_{2,1}$ & -0.177 & $(0.073)$ & - & - \\
\hline$Q(20)$ & 23.1906 & {$[0.2795]$} & 24.4184 & {$[0.2246]$} \\
\hline$Q^{2}(20)$ & 11.7691 & {$[0.9238]$} & 12.4682 & {$[0.8990]$} \\
\hline$L M_{S C}$ & 26.9826 & {$[0.1358]$} & - & - \\
\hline AIC & \multicolumn{2}{|c|}{11892.696} & \multicolumn{2}{|c|}{11899.471} \\
\hline Log Lik & \multicolumn{2}{|c|}{-5937.3480} & \multicolumn{2}{|c|}{-5945.7354} \\
\hline
\end{tabular}

Note: Standard errors are given in parentheses. 
The second stage of the analysis is the estimation of $\operatorname{AR}(2)-\operatorname{FITVGARCH}(1, d, 1)$ for the DJIM. We use a two step estimation procedure, i.e. estimating an $\operatorname{AR}(2)$ model first, and then taking the residuals to fit the $\operatorname{FITVGARCH}(1, d, 1)$ model. The estimation of the $\operatorname{FITVGARCH}(1, d, 1)$ is based on the quasi maximum likelihood estimation procedure. The results are presented in the first two columns of Table 2. Columns 1 shows parameter estimates while standard errors are given in columns 2. For comparison purposes, we also estimate an $\operatorname{AR}(2)$-FIGARCH$(1, d, 1)$ model where the parameter estimates and their asymptotic standard errors are reported, respectively, in the last two columns of of Table 2. The long memory parameter $\hat{d}$ is significantly different from zero for both models; of about 0.474 for the FITVGARCH model and 0.489 for the FIGARCH model. The significance of $d$ indicates strong evidence of long memory in the volatility process. The conditional variance parameters of the FITVGARCH model are highly significant, except for the $\hat{\omega}_{2}$ parameter which indicates that there is no change in the constant coefficient of the variance equation. For the FIGARCH model, the parameter $\hat{\phi}_{1}$ is not significant, while the parameters $\hat{\omega}$ and $\hat{\beta}_{1}$ are significant at 5\% level. Looking now at the transition function parameters in the FITVGARCH model, the estimated threshold parameter $\hat{c}=0.732$ is highly significant and indicates that the structural change of the volatility structure occurred at about the time point $\hat{t}=0.732 \times T,(\hat{t} \simeq 3350$, i.e., November, 4 , 2008), where $T$ is the number of observations. The value of the smoothness parameter $(\hat{\gamma}=96.907)$ implies a smooth change in the parameters of the variance equation. This can also be observed from the first panel of Figure 2 which plots the logistic transition function. It is clear that the transition between the extreme regimes is smooth.

Some diagnostics on the residuals obtained from both models are shown 


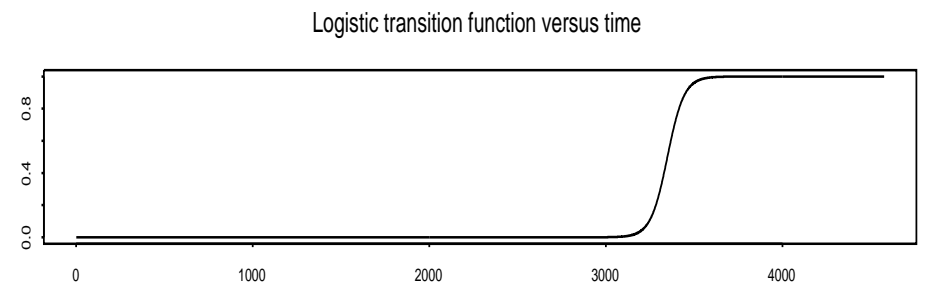

Conditional standard deviation from FITVGARCH

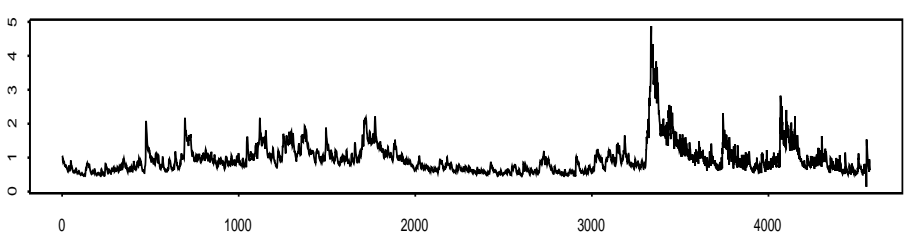

Conditional standard deviation from FIGARCH

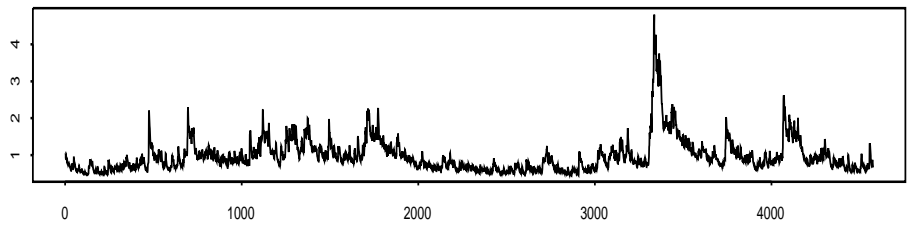

Figure 2: Estimated logistic transition function from the FITVGARCH model and conditional standard deviation.

in Table 2. The Ljung Box portmanteau tests for up to 20th-order serial correlation in the residuals and squared residuals indicates that the hypothesis of serial dependence, up to order 20, is strongly rejected for both models. In addition, the misspecification test, according to $L M_{S C}$ statistic, indicates that the squared standardized errors from the FITVGARCH model does not seem to be autocorrelated up to the 20th order. Comparison of FIGARCH and FITVGARCH in terms of the diagnostics and information criteria, reveals that FITVGARCH model perform better than the FIGARCH model. In- 
deed, both log-likelihood and AIC values are favorable for the FITVGARCH model relative to the FIGARCH model. Not surprisingly, similar results were obtained for daily data on the returns for the NASDAQ composite stock index by Ben Nasr et al., (2010), thus, in turn, highlighting the need to model simultaneously long-memory and structural changes in the volatility process of asset returns.

\section{Conclusions}

In the wake of the recent global financial crisis, a need has risen for a renovation of the conventional financial systems, and this, in turn, has resulted in a steady increase in renewed interest in Islamic finance as a viable financial system that can be used as an opportunity to diversify away the systematic risk in conventional portfolios. In essence, Islamic finance may offer products and instruments that are governed by greater social responsibility, ethical and moral values and sustainable finance, and hence, can possibly endure financial crises better than the conventional system. Given this, in this paper, we aim to model conditional volatility of the returns of the Dow Jones Islamic Market World Index (DJIM), accounting for both long memory and structural changes in the volatility process. The choice of the DJIM is justified by the fact that it is the most widely used, most comprehensive representative, and has the most adequate time series for the Islamic stock market. Note that, appropriate modeling of the process of volatility has implications for portfolio selection, the pricing of derivative securities and risk management.

A large body of research suggests that there is significant evidence of long memory in the conditional volatility of various financial and economic time series, while, another related discussion on financial time series suggests that 
there is strong evidence for the occurrence of structural changes in the volatility process. In light of these two features, a body of research has suggested that both long memory and structural changes simultaneously characterize the structure of financial returns volatility. Motivated from the latter line of research, following Ben Nasr et al., (2010), we estimate a model for the DJIM returns that allows the volatility of the returns to be characterized by both long memory and structural changes. The idea is to allow the parameters in the conditional variance equation of the FIGARCH model to be time dependent, by allowing the change of the parameters to evolve smoothly over time using a logistic smooth transition function, which, in turn yields a FITVGARCH model. Our results show that, in terms of model diagnostics and information criteria, the FITVGARCH model performs better than the FIGARCH model in explaining conditional volatility of the DJIM returns, thus, in turn, highlighting the need to model simultaneously long-memory and structural changes in the volatility process of asset returns. Given that better in-sample fit does not necessarily translate into superior out-of-sample forecasts (Rapach and Zhou, 2013), an immediate extension of the current study would be to compare the forecasting ability of the FIGARCH and FITVGARCH, and possibly other set of standard models describing volatility of asset returns, as in Lux (2008), Lux and Morales-Arias (2010), Lux et al., (2011).

\section{References}

[1] Amado C, Teräsvirta T (2008) Modelling Conditional and Unconditional Heteroskedasticity with Smoothly Time-Varying Structure. SSE/EFI Working Paper Series in Economics and Finance No. 691 
[2] Anderson HM, Nam K, Vahid F (1999) Asymmetric nonlinear smooth transition GARCH models. In: Rothman P (ed) Nonlinear time series analysis of economic and financial data, Kluwer, Boston, pp 191-207

[3] Andersen TG Bollerslev T (1997) Heterogeneous information arrivals and return volatility dynamics: uncovering the long-run in high frequency returns. Journal of Finance 52:975-1005.

[4] Andreou E, Ghysels E (2002) Detecting multiple breaks in financial market volatility dynamics. Journal of Applied Econometrics 17:579-600.

[5] Baillie RT, Bollerslev T, Mikkelsen H (1996) Fractionally integrated generalized autoregressive conditional heteroskedasticity. Journal of Econometric $74: 3-30$

[6] Baillie RT, Han YW, Kwon T (2002) Further long memory properties of inflationary shocks. Southern Economic Journal 68:496-510.

[7] Baillie RT, Morana C (2007) Modeling Long Memory and Structural Breaks in Conditional Variances: an Adaptive FIGARCH Approach. ICER, Working Paper No. 11/2007.

[8] Beine M, Laurent S (2000) Structural change and long memory in volatility: new evidence from daily exchange rates. working paper, University of Liege.

[9] Ben Nasr A, Boutahar M, Trabelsi A (2010) Fractionally integrated time varying GARCH model. Statistical Methods and Applications 19(3): 399-430.

[10] Berkes I, Horvath L, Kokoszka P (2003) GARCH processes: structure and estimation. Bernoulli 9:201-228 
[11] Berndt E, Hall B, Hall R, Hausman J (1974) Modelling the persistence of conditional variances. Annals of Economic and Social Measurement $3: 653-665$

[12] Bollerslev T (1986) Generalized autoregressive conditional heteroskedasticity. Journal of Econometrics 31:307-327

[13] Bollerslev T, Engle RF (1993) Common persistence in conditional variances. Econometrica 61:167-186

[14] Bollerslev T, Mikkelsen HO (1996) Modelling and Pricing Long Memory in Stock Market Volatility. Journal of Econometrics 73:151-184

[15] Bollerslev T, Wooldridge JM (1992) Quasi Maximum Likelihood Estimation and Inference in Dynamic Models with Time Varying Covariances. Econometric Reviews 11:143-172

[16] Bos CS, Franses PH, Ooms M (1999) Long memory and level shifts: re-analyzing inflation rates. Empirical Economics 24:427-449

[17] Breidt FJ, Crato N, de Lima P (1998) Modeling long memory stochastic volatility. Journal of Econometrics 83:325-348.

[18] Breidt FJ, Hsu NJ (2002) A class of nearly long-memory time series models. International Journal of Forecasting 18:265-281

[19] Brown RL, Durbin J, Evans JM (1975) Techniques for testing the constancy of regression relationships over time with comments. Journal of the Royal Statistical Society B37:149-192

[20] Chung CF (1999) Estimating the fractionally integrated GARCH model. National Taiwan University, Taipei, TW 
[21] Cai J (1994) A Markov model of regime-switching ARCH. Journal of Business and Economic Statistics 12:309-316

[22] Conrad C, Haag BR (2006) Inequality constraints in the fractionally integrated GARCH model. Journal of Financial Econometrics 4:413-449

[23] Davidson JEH (2004a) Conditional heteroskedasticity models and a new model. Journal of Business and Economic Statistics 22:16-29

[24] Davidson J (2004b) Moment and Memory Properties of Linear Conditional Heteroscedasticity Models, and a New Model. Journal of Business and Economic Statistics 22:16-19

[25] Diebold FX (1986) Comment on "Modeling the persistence of conditional variance". by Engle R, Bollerslev T. Econometric Reviews 5:5156

[26] Ding Z, Granger CWJ, Engle RF (1993) A long memory property of stock market returns and a new model. Journal of Empirical Finance $1: 83-106$

[27] Dueker MJ (1997) Markov switching in GARCH processes and meanreverting stock market volatility. Journal of Business and Economic Statistics 12:309-316

[28] Efron B, Hinkley D (1978) Assessing the accuracy of the maximum likelihood estimator: Observed versus expected Fisher information. Biometrika 65:457-482

[29] Eitrheim , Teräsvirta T (1996) Testing the Adequacy of Smooth Transition Autoregressive Models. Journal of Econometrics 74:59-75 
[30] Engle RF (1982) Autoregressive conditional heteroskedasticity with estimates of the variance of UK inflation. Econometrica 50:987-1008

[31] Engle RF, Bollerslev T (1986) Modeling the persistence of conditional variances. Econometric Reviews 5:1-50

[32] Engle RF, Rangel JG (2008) The spline-GARCH model for low frequency volatility and its global macroeconomic causes. Review of Financial Studies 21:1187-1222

[33] Gonzalez-Rivera G (1998) Smooth transition GARCH models. Studies in Nonlinear Dynamics and Econometrics 3:161-178

[34] Granger CWJ (1981) Some properties of time series data and their use in econometric model specification. Journal of Econometrics 16:121-130

[35] Granger CWJ, Hyung N (2004) Occasional structural breaks and long memory with an application to the S\&P 500 absolute stock returns. Journal of Empirical Finance 11:399-421

[36] Granger CWJ, Joyeux R (1980) An introduction to long-memory time series and fractional differencing. Journal of Time Series Analysis 1:1539

[37] Hagerud G (1997) A new non-linear GARCH model. EFI Economic Research Institute, Stockholm.

[38] Hamilton JD, Susmel R (1994) Autoregressive conditional heteroscedasticity and changes in regime. Journal of Econometrics 64:307-333

[39] Hammoudeh S, Jawadi F, Sarafrazi S (2013) Interactions between conventional and islamic stock markets: a hybrid threshold analysis. Mimeo, Drexel University, PA, U.S.A. 
[40] Jensen ST, Rahbek A (2004) Asymptotic inference for nonstationary GARCH. Econometric Theory 20:1203-26.

[41] Karanasos M, Psaradakis Z, Sola M (2004) On the autocorrelation properties of long-memory GARCH processes. Journal of Time Series Analysis $25: 265-281$

[42] Lamoureux CG, Lastrapes WD (1990) Persistence in variance, structural change and the GARCH model. Journal of Business and Economic Statistics 8:225-34

[43] Lee SW, Hansen BE (1994) Asymptotic theory for the $\operatorname{GARCH}(1,1)$ quasi-maximum likelihood estimator. Econometric Theory 10:29-52

[44] Lin CFJ, Teräsvirta T (1994) Testing the Constancy of Regression Parameters Against Continuous Structural Change. Journal of Econometrics 62:211-28

[45] Lobato IN, Savin NE (1998) Real and spurious long memory properties of stock market data. Journal of Business and Economic Statistics $16: 261-268$

[46] Lumsdaine RL (1996) Consistency and asymptotic normality of the quasi-maximum likelihood estimator in $\operatorname{IGARCH}(1,1)$ and covariance stationary GARCH $(1,1)$ models. Econometrica 64:575-596

[47] Lundbergh S, Teräsvirta T (2002) Evaluating GARCH Models. Journal of Econometrics 110:417-435

[48] Luukkonen R, Saikkonen P, Teräsvirta T (1988) Testing linearity against smooth transition autoregressive models. Biometrika 75:491-499 
[49] Lux T (2008) The Markov-switching multifractal model of asset $r$ eturns: GMM estimation and linear forecasting of volatility. Journal of Business and Economic Statistics 26:194-210

[50] Lux T, Morales-Arias, L (2010) Forecasting volatility under fractality, regime-switching, long memory and student-t innovations. Computational Statistics and Data Analysis 54:2676-2692

[51] Lux T, Morales-Arias, L, Sattarhoff C (2011) A Markov-switching multifractal approach to forecasting realized volatility. Kiel Institute for the World Economy Working Paper 1737.

[52] Martens M, van Dijk D, de Pooter M (2004) Modeling and forecasting S\&P 500 volatility: long memory, structural breaks and nonlinearity. Tinbergen Institute Discussion Paper 04-067/4.

[53] Mikosch T, Stărică C (2004) Changes of structure in financial time series and the GARCH model. Revstat Statistical Journal 2(1):41-73

[54] Morana C, Beltratti A (2004) Structural change and long-range dependence in volatility of exchange rates: either, neither or both? Journal of Empirical Finance 11:629-658

[55] Nelson DB (1991) Conditional heteroskedasticity in asset returns: a new approach. Econometrica 59:347-370

[56] Nelson DB, Cao CQ (1992) Inequality constraints in the univariate GARCH model. Journal of Business and Economic Statistics 10:229235 
[57] Perron P, Qu Z (2007) An Analytical Evaluation of the LogperiodogramEstimate in the Presence of Level Shifts. Unpublished Manuscript, Department of Economics, Boston University.

[58] Perron P, Qu Z (2008) Long-Memory and Level Shifts in the Volatility of Stock Market Return Indices. Unpublished Manuscript, Department of Economics, Boston University.

[59] Rapach DE, Strauss, JK (2008) Structural breaks and GARCH models of exchange rate volatility. Journal of Applied Econometrics 23(1): 6590

[60] Rapach DE, Strauss, JK, Wohar, ME (2008) Forecasting stock return volatility in the presence of structural breaks. In Forecasting in the Presence of Structural Breaks and Model Uncertainty, David E. Rapach and Mark E. Wohar (Eds.), Vol. 3 of Frontiers of Economics and Globalization, Bingley, United Kingdom, Emerald: 381-416

[61] Rapach DE, Zhou G (2013) Forecasting stock returns. In Graham Elliott and Allan Timmermann (Eds.), Handbook of Economic Forecasting, Vol. 2: 328-383.

[62] Robinson PM (1991) Testingfor strong serial correlation and dynamic conditional heteroskedasticity in multiple regression. Journal of Econometrics 47:67-84

[63] So MKP, Lam K, Li NK (1998) A stochastic volatility model with Markov switching. Journal of Business and Economic Statistics $16(2): 244-253$

[64] Stărică C, Granger C (2005) Nonstationarities in Stock Returns. Review of Economics and Statistics 87:503-522 
[65] Teyssière G (1997) Double long-memory financial time series. Paper presented at the ESEM, Toulouse.

[66] Tsai H, Chan KS (2008) A note on inequality constraints in the GARCH model. Econometric Theory 24:823-828

[67] Tse YK (1998) The conditional heteroskedasticity of the Yen-Dollar exchange rate. Journal of Applied Econometrics 13:49-55

[68] White H (1982) Maximum likelihood estimation of misspecified models. Econometrica 50:1-25 